\title{
Adolescents and young adults with cancer: aspects of adherence - a questionnaire study
}

\author{
Anne Marie Kleinke \\ Carl Friedrich Classen \\ Oncology and Hematology Unit, \\ Children's Hospital, University \\ Medicine Rostock, Rostock, Germany
}

This article was published in the following Dove Press journal: Adolescent Health, Medicine and Therapeutics

Purpose: For adolescents and young adults (AYAs), a cancer diagnosis represents an extraordinary strike in a vulnerable phase of life. They have special needs that the medical system has to take into consideration, and they exhibit a lower degree of therapy adherence than both older and younger patients. The purpose of this study was first to analyze the adherence of AYAs with cancer compared to a group of older patients and, second, to determine correlated parameters, with focus on the psychosocial interaction between physicians and patients.

Patients and methods: In 2012, a complete 1 year cohort of patients reported, by use of a questionnaire, to the Rostock clinical cancer registry, and a group of older patients were invited to answer a multi-item set of questionnaires on a volunteer basis, leading to a population-based cross-sectional analysis. This included a bias due to non-answering which is unavoidable in such a setting. The questionnaire consisted of well-established standard questionnaires, a questionnaire on adherence that has just recently been published, and a self-written questionnaire focusing on patient-physician relationship. The responses were analyzed for our current study.

Results: Gender, religion, education, age, anxiety, family atmosphere, or physician-patient relationship were not significantly correlated to adherence in AYAs. However, markedly more AYAs, as compared to the older patients group, considered breaking off therapy and reported suboptimal communication with the physicians. Only the perceived physical illness could be identified as a factor related to adherence among the AYA group.

Conclusion: Our findings confirm the need for more focused approaches to serve the special needs of AYAs, with particular attention on specific items that showed up discriminating AYAs from older patients, that is, Internet use and communication with physicians. Here, further research is needed to examine adherence to specific treatment protocols.

Keywords: adherence, adolescents and young adults, special needs, psychosocial interaction

\section{Introduction}

Adolescents and young adults (AYAs) are at an age in which education, choice of profession, sexuality, starting a family, and other aspects of a meaningful life are at a crossroads. For this age group, a cancer diagnosis represents an additional challenge in a vulnerable phase of life. AYAs differ both from older adults and children with regard to medical and psychosocial aspects. In the new millennium, this has increasingly been acknowledged by the cancer community. ${ }^{1}$ In the medical literature, different definitions of AYAs are used, with the lower limit ranging from 15 to 18, and the upper limit from 25 to 40 years of age. ${ }^{1}$ Within the cancer population, they represent a minority: in Germany, only about $5 \%$ of people diagnosed with cancer ${ }^{2}$ are younger than 40 years. ${ }^{3}$ The current survival rate of AYA patients with cancer has improved to a lower degree
Correspondence: Carl Friedrich Classen Children's Hospital, University Medicine Rostock, Ernst-Heydemann-Str. 8,

D-I8057 Rostock, Germany

Tel +493814947262

Fax +493814947261

Email carl-friedrich.classen@med.unirostock.de 
as compared to both younger and older patients in the last 20 years. ${ }^{4-7}$ Besides biological factors, the disease course of AYAs with cancer is affected by age-specific psychosocial characteristics $^{3,8}$ and many other aspects of life, ${ }^{8-12}$ and late effects have a much higher impact on them. ${ }^{13}$ Psychosocial regression ${ }^{14}$ or delayed social maturity, depression, anxiety, mood changes as well as health concerns and relationship problems may be relevant, ${ }^{15,16}$ thus family support and cohesiveness may help for positive adaptation. ${ }^{17}$

Adherence by definition is the degree to which a sick person adheres to agreed recommendations regarding taking medication, following a diet, or executing lifestyle changes. ${ }^{18}$ Especially in malignancies, the success of therapy largely depends on the patients' adherence. The World Health Organization (WHO) has published a model of adherence, associating it with socioeconomic, health system, condition, patient, and therapy-related factors. ${ }^{19}$ Several data indicate that adherence is poorer in AYAs than in both older and younger patients. ${ }^{20-22}$

There are different methods to measure adherence, ${ }^{23}$ including objective monitoring; ${ }^{24-26}$ patient questioning, however, is more feasible in many conditions and also is an established way to receive reliable data. ${ }^{18}$ Several studies report that gender, ${ }^{27}$ ethnicity, and socioeconomic status do not influence adherence of AYAs, ${ }^{18,28}$ with family environment and physician-patient relationship being of greater importance. ${ }^{28,29}$ Physician-patient relationship is a key factor, including friendliness and accessibility, patient-centered medicine, and psychological dimensions. ${ }^{30,31}$ Insufficient adherence can compromise therapeutic success ${ }^{32}$ and disrupt the therapeutical process in many ways, ${ }^{33-35}$ finally resulting in poorer outcomes. ${ }^{36}$

This work is based on a population-based questionnaire study regarding the psychosocial well-being of a cohort of AYA cancer patients in the area of Rostock, Germany, including a comparison group of older patients. These data were analyzed in order to determine parameters correlated to adherence. The roles of gender, religion, education, anxiety, perceived illness; relationship between AYAs and their parents; and physician-patient relationship ${ }^{28}$ were analyzed.

\section{Patients and methods}

Our study is based on the complete population of patients reporting to the Rostock clinical cancer registry in 2012 (date of diagnosis between January 1, 2012 and December 31,2012 ); by use of a questionnaire. This registry covers an area of 570,000 inhabitants and encompasses $\sim 93 \%$ of all cancer patients in this region. ${ }^{37}$ Our study was approved by the ethical committee of the Medical Faculty of the University of Rostock (A2011-135). All patients or their parents/legal guardians if under 18 years of age provided written informed consent to participate in the questionnaire survey.

\section{Participants}

All registered patients diagnosed with cancer between their 15 th and 40th birthday were invited to participate, as were 100 randomly selected older patients who served as a comparison group.

\section{Procedure}

The patients were sent a letter within the first 8 weeks following first diagnosis, but not earlier than 2 weeks after diagnosis. The letter comprised the following items: 1) covering letter, 2) patient information, 3) patient consent form, and 4) questionnaire set. A stamped envelope for postal return was included. Patients not answering within 8 weeks were called once via telephone or contacted via postcard and were once more encouraged to participate. After return of the answer sheets, the records were entered in an SPSS database manually.

The questionnaire was compiled by the cooperative working group "AYAROSA" at the Rostock University of Medicine (AYAROSA stands for Adolescents and young adults - Rostocker Aufbruch; meaning Rostock uplift). The aim of the questionnaire study was to assess numerous aspects of the psychosocial conditions of cancer patients; however, for the analysis following here, the focus was put on the question of adherence.

\section{Materials}

For the item adherence, the English-language scale "nonadherence scale" by Kondryn et al was used with permission of the authors ${ }^{38}$ and translated into German; the permission included reproduction. This questionnaire measures nonadherence in cancer patients, differentiating between lowrisk and high-risk adherence by using a 5-point Likert scale containing the values 0 (non-adherence never occurs) to 4 (non-adherence always occurs).

The German equivalent of Hospital Anxiety and Depression Scale $(\mathrm{HADS})^{39}$ was used for the parameter anxiety. It consists of seven questions, each assessing anxiety and depression with four reply options (from agreement to refusal). In our study, anxiety was determined by the cumulative value HADS-D-Angst (sum A).

The item perceived illness ${ }^{40-43}$ was measured by the internationally known questionnaire Short Form 36 (SF-36), German version, assessing the health-related quality of life by means of 36 questions. SF-36 consists of eight dimensions of subjective health: physical function, physical role 
function, physical pain, general health perception, vitality, social function, emotional function, and mental well-being. Thus, the perceived physical illness (KSK) and the perceived mental distress (PSK) are defined.

The constructs family environment and physicianpatient relationship were examined on the basis of a self-written AYAROSA questionnaire (Supplementary material). It accounts for sociodemographic factors, handling of diagnosis and therapy, and physician-patient relationship. Family environment includes two items ("As a child I could talk about everything with my mother and/ or my father;" "I can talk about all my problems with my mother and/or with my father"), whereas physician-patient relationship included 23 items. A 4-point Likert scale was used, ranging from completely true to completely false. Four different items were recoded and indicated with $r$. Furthermore, the questionnaire entailed a free text field for notes or ambiguities.

A total of 243 AYA patients with a median of 30 years of age (from 18 to 39 years) were contacted, as were 100 patients with a median of 66.5 years of age (from 47 to 76 years) who constituted the comparison group.

\section{Data analysis}

The analysis of the raw questionnaire data included the following steps:
- Analysis of the response sample. This included description of age, gender characteristics, diagnosis, and so on.

- Comparison of raw data between the AYA and the group of older patients. Here, primarily by two-sample $t$-test, focusing on the AYAROSA questionnaire, differences between the two age groups were identified.

- Search for conditions possibly correlated to adherence. The adherence, as measured by the questionnaire of Kondryn et al, ${ }^{38}$ was - after corrections to improve Cronbach's alpha - analyzed with regard to other variables measured within the questionnaire set, in order to identify conditions possibly correlated to adherence.

\section{Results \\ Description of the sample}

In total, $36.2 \%(88 / 243)$ of AYAs and $33.0 \%(33 / 100)$ of the comparison group responded. Eight individuals rejected participation, one person had passed away, and 12 had changed their place of residence. In conclusion, we were able to generate 122 data sets. In the AYA group, the average age was 30.6 years, with a standard deviation of 5.2 years. The age range was between 18 and 39 years (Figure 1A). Seventy-four women (83.1\%) and 15 men (16.9\%) responded, while 157 patients failed to reply $(36.2 \%)$.

In the older age group, the average age was 66.1 years with a standard deviation of 9.23 years; the age range was

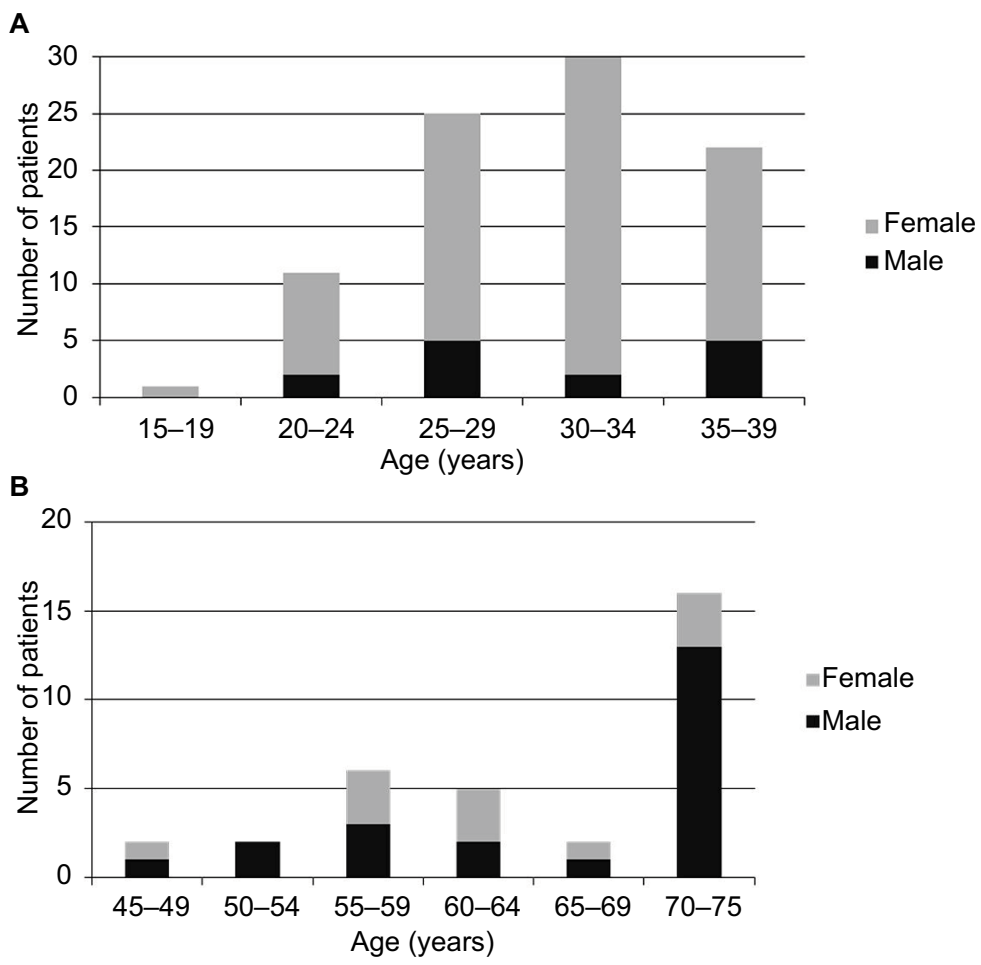

Figure I Age distribution of the patients.

Notes: (A) Age distribution of the adolescents and young adults (AYAs). (B) Age distribution of the comparison group. 
between 47 and 76 years (Figure 1B). This group initially consisted of 35 women and 65 men. Eleven women $(33.3 \%)$ and 22 men (66.67\%) responded, whereas 11 individuals rejected participation, three had passed away, and another three had changed their place of residence. From 61 patients, we received no answer; resulting in a response rate of $33.0 \%$ for the comparison group. For the distribution of the diagnoses and the demographic data, see Table 1.

Within the questionnaire, not all patients answered all questions, leaving the number of responses for some of the questions even lower.

Table I Demographic data of AYAs and the comparison group

\begin{tabular}{|c|c|c|c|}
\hline & & AYAs & $\begin{array}{l}\text { Comparison } \\
\text { group }\end{array}$ \\
\hline \multirow[t]{11}{*}{ Diagnosis } & Gynecological & $\begin{array}{l}50.1 \% \\
\text { (cervical } \\
\text { intraepithelial } \\
\text { neoplasia III: } \\
\text { 42.1\%; } \\
\text { breast: } 8.0 \% \text { ) }\end{array}$ & - \\
\hline & Hematological & $10.2 \%$ & $6.1 \%$ \\
\hline & Gastrointestinal tract & $5.7 \%$ & $21.2 \%$ \\
\hline & Respiratory tract & - & $21.2 \%$ \\
\hline & Urological & $3.4 \%$ & $\begin{array}{l}30.3 \% \\
\text { (prostate: } \\
24.2 \% \text {; urinary } \\
\text { tract: } 6.1 \% \text { ) }\end{array}$ \\
\hline & $\begin{array}{l}\text { Endocrinological (especially } \\
\text { thyroid) }\end{array}$ & $6.8 \%$ & - \\
\hline & Dermatological & $17.0 \%$ & $15.2 \%$ \\
\hline & Ophthalmological & - & $3.0 \%$ \\
\hline & Otolaryngological & - & $3.0 \%$ \\
\hline & Brain tumors & $5.7 \%$ & - \\
\hline & Bone tumors & $1.1 \%$ & - \\
\hline \multirow[t]{5}{*}{$\begin{array}{l}\text { Educational } \\
\text { status }\end{array}$} & $\begin{array}{l}\text { No school degree/ } \\
\text { special school }\end{array}$ & $4.6 \%$ & - \\
\hline & Lower secondary school & $14.9 \%$ & $21.9 \%$ \\
\hline & Secondary school & $42.5 \%$ & $40.6 \%$ \\
\hline & High school qualification & $37.9 \%$ & $34.4 \%$ \\
\hline & Higher education degree & $17.2 \%$ & $18.8 \%$ \\
\hline Work & Employee & $65.9 \%$ & $14.3 \%$ \\
\hline \multirow[t]{5}{*}{ status } & Unemployed & $15.9 \%$ & $14.3 \%$ \\
\hline & Pensioner & - & $71.4 \%$ \\
\hline & Pupil & $1.1 \%$ & - \\
\hline & Trainee/college student & $9.0 \%$ & - \\
\hline & Other & $8.0 \%$ & - \\
\hline \multirow[t]{4}{*}{ Residence } & With parents & $4.7 \%$ & - \\
\hline & Own flat & $90.6 \%$ & $100.0 \%$ \\
\hline & $\begin{array}{l}\text { Moved back in with } \\
\text { parents }\end{array}$ & $2.4 \%$ & - \\
\hline & $\begin{array}{l}\text { Reside with both parents } \\
\text { and at place of schooling }\end{array}$ & $2.4 \%$ & - \\
\hline \multirow[t]{3}{*}{ Religion } & No religion & $90.7 \%$ & $56.6 \%$ \\
\hline & Protestant & $9.3 \%$ & $31.0 \%$ \\
\hline & Catholic & - & $10.3 \%$ \\
\hline
\end{tabular}

Abbreviation: AYAs, adolescents and young adults.

\section{Comparison of raw data between the AYAs and the older age group}

Due to the number of data, only those results that were relevant for the analysis of adherence, with focus on the AYAROSA questionnaire, are shown. Several respondents left individual points of the questionnaire unanswered; therefore, the absolute number of answers is not always the same.

First, we analyzed the results using a group comparison between the AYAs and older age group by two-sample $t$-test in the AYAROSA questionnaire. The analysis showed significant group differences in 11 of 41 items (Table 2).

The most interesting results were the following: when feeling uncertain about medical questions, AYAs diagnosed with cancer used the Internet significantly more often than the comparison group. They more frequently stated that they had already received therapies which the physicians had not explained in detail beforehand $(9.4 \%$ for AYA patients vs $3.3 \%$ ) and that physicians should learn to improve their communication skills (27.1\% vs 16.6\%). More AYAs considered breaking off therapy in part (17.7\% vs $3.4 \%)$, and $12 \%$ of

Table 2 Significant group differences between AYA and CG in AYAROSA questionnaire

\begin{tabular}{|c|c|c|c|c|}
\hline & & $n$ & Mean & Significance \\
\hline $\begin{array}{l}\text { I regard the therapy as a } \\
\text { challenge I have accepted for } \\
\text { myself }\end{array}$ & $\begin{array}{l}\text { CG } \\
\text { AYAs }\end{array}$ & $\begin{array}{l}29 \\
78\end{array}$ & $\begin{array}{l}1.4 \\
2.2\end{array}$ & $<0.001$ \\
\hline I feel well informed & $\begin{array}{l}\text { CG } \\
\text { AYAs }\end{array}$ & $\begin{array}{l}32 \\
88\end{array}$ & $\begin{array}{l}1.5 \\
1.9\end{array}$ & 0.021 \\
\hline $\begin{array}{l}\text { I decide about my own therapy; } \\
\text { the doctors act only as my } \\
\text { consultants }\end{array}$ & $\begin{array}{l}\text { CG } \\
\text { AYAs }\end{array}$ & $\begin{array}{l}28 \\
83\end{array}$ & $\begin{array}{l}1.4 \\
2.0\end{array}$ & $<0.001$ \\
\hline $\begin{array}{l}\text { When entering the hospital, I } \\
\text { feel reluctant }\end{array}$ & $\begin{array}{l}\text { CG } \\
\text { AYAs }\end{array}$ & $\begin{array}{l}30 \\
83\end{array}$ & $\begin{array}{l}3.5 \\
2.9\end{array}$ & 0.001 \\
\hline $\begin{array}{l}\text { I would share my most personal } \\
\text { problems with my doctor }\end{array}$ & $\begin{array}{l}\text { CG } \\
\text { AYAs }\end{array}$ & $\begin{array}{l}30 \\
84\end{array}$ & $\begin{array}{l}2.0 \\
2.6\end{array}$ & 0.017 \\
\hline $\begin{array}{l}\text { I think doctors would } \\
\text { do well to improve their } \\
\text { communication skills }\end{array}$ & $\begin{array}{l}\text { CG } \\
\text { AYAs }\end{array}$ & $\begin{array}{l}30 \\
84\end{array}$ & $\begin{array}{l}3.4 \\
3.0\end{array}$ & 0.018 \\
\hline $\begin{array}{l}\text { I am happy to receive all } \\
\text { information in an objective, } \\
\text { non-emotional manner; I can } \\
\text { cry when I am alone }\end{array}$ & $\begin{array}{l}\text { CG } \\
\text { AYAs }\end{array}$ & $\begin{array}{l}32 \\
87\end{array}$ & $\begin{array}{l}1.3 \\
2.0\end{array}$ & $<0.001$ \\
\hline $\begin{array}{l}\text { I have the feeling that my } \\
\text { doctors are indifferent toward } \\
\text { my worries }\end{array}$ & $\begin{array}{l}\text { CG } \\
\text { AYAs }\end{array}$ & $\begin{array}{l}31 \\
85\end{array}$ & $\begin{array}{l}3.8 \\
3.4\end{array}$ & 0.003 \\
\hline $\begin{array}{l}\text { It is important to me that my } \\
\text { hospital room is cozy }\end{array}$ & $\begin{array}{l}\text { CG } \\
\text { AYAs }\end{array}$ & $\begin{array}{l}27 \\
79\end{array}$ & $\begin{array}{l}1.3 \\
1.8\end{array}$ & 0.005 \\
\hline $\begin{array}{l}\text { I have already had examinations } \\
\text { without anyone explaining them } \\
\text { to me beforehand }\end{array}$ & $\begin{array}{l}\text { CG } \\
\text { AYAs }\end{array}$ & $\begin{array}{l}30 \\
83\end{array}$ & $\begin{array}{l}3.7 \\
3.2\end{array}$ & 0.005 \\
\hline $\begin{array}{l}\text { I have considered breaking off } \\
\text { therapy completely }\end{array}$ & $\begin{array}{l}\text { CG } \\
\text { AYAs }\end{array}$ & $\begin{array}{l}28 \\
80\end{array}$ & $\begin{array}{l}3.9 \\
3.7\end{array}$ & 0.038 \\
\hline
\end{tabular}

Abbreviations: AYAs, adolescents and young adults; CG, comparison group. 
the AYAs considered breaking off the therapy entirely, which none of the older ones considered. AYAs were more likely to entertain thoughts of pursuing alternative medical methods (19.5\% vs $10.3 \%$ ). In particular, the AYAs did not agree with the statement "I decide about my own therapy; the doctors act only as my consultants" (25.9\% for AYAs vs $3.6 \%)$.

\section{Conditions correlated to adherence}

For the definition of the construct adherence, according to Kondryn et al, ${ }^{38}$ items with an item-correlation $<0.3$ were to be expelled when yielding an increase in Cronbach's alpha. Thus, a measuring instrument resulted, consisting of six items (Table 3). Concerning the physician-patient relationship, four items were recoded, and 23 items were incorporated yielding a Cronbach's alpha $=0.870$, which rose to 0.889 , after deleting four items.

The testing of the constructs gender, religion, education, and age (Table 4) demanded a different approach. We determined that patient adherence of AYAs is independent

Table 3 Items used for the construct non-adherence

Items used for the construct non-adherence
How often do you forget to take your oral medicine?
Have you ever taken your oral medicine at a wrong time?
If you feel good, have you ever ceased to take your different oral
medicine?
If you feel worse, have you ever ceased to take your different oral
medicine?
Have you ever missed an out-patient appointment?
Have you ever forgotten to do your oral hygiene?

Table 4 Mean values of non-adherence according to patient groups

\begin{tabular}{lllll}
\hline Group & Number & Mean & $\begin{array}{l}\text { Standard } \\
\text { deviation }\end{array}$ & $\begin{array}{l}\text { Standard } \\
\text { error of mean }\end{array}$ \\
\hline AYAs & 62 & 1.4 & 2.0 & 0.3 \\
Comparison group & 25 & 1.0 & 1.1 & 0.2 \\
\hline
\end{tabular}

Abbreviation: AYAs, adolescents and young adults. of gender and age; tested by two-sample $t$-test. Furthermore, adherence of the AYA group is independent of religion $(p$-value $=0.526>0.05)$ and education $(p$-value $=0.439>$ $0.05)$; this was tested by ANOVA. The examination of the constructs physician-patient relationship, perceived physical illness, perceived mental distress, anxiety, and family environment necessitated a regression analysis (Table 5).

According to this study, gender, religion, education, age, anxiety, the perceived mental distress, family atmosphere, and physician-patient relationship are not significantly correlated to adherence of AYAs. From Table 5, it should be noted that a high value on the non-adherence scale corresponds to a lower adherence. Accordingly, negative regression coefficients mean that a higher value of the individual regressors means an improvement of adherence. Only the perceived physical illness with a $p$-value of 0.027 showed a significant correlation to the adherence of AYA patients. The regression function resulted in the following equation: non-adherence $=8.165-0.059 *$ perceived physical illness.

\section{Discussion}

In light of the limited research concerning adherence in AYAs with cancer, we conducted a study on adherence in this age group and compared it to adherence in older patients. This was based on data from a multi-item questionnaire study which was done in 2012. Known weaknesses of our work are the number of responders and reliance on self-reports, without objective indicators; furthermore, use of in part nonvalidated measures.

In line with previous literature, ${ }^{19-22}$ our results suggest that AYA patients with cancer display an insignificantly lower degree of adherence compared to older patients. A markedly higher degree of AYAs consider breaking off their therapy in part or even completely.

Table 5 Regression analysis: physician-patient relationship, perceived physical illness (KSK), perceived mental distress (PSK), anxiety, family environment related to adherence

\begin{tabular}{|c|c|c|c|c|c|c|c|}
\hline \multirow{2}{*}{$\begin{array}{l}\text { Model } \\
\mathrm{I}\end{array}$} & $\mathbf{R}$ & $\mathbf{R}^{2}$ & \multicolumn{2}{|c|}{$\begin{array}{l}\text { Corrected } \\
\mathbf{R}^{2}\end{array}$} & $\begin{array}{l}\text { Standard error } \\
\text { of assessor }\end{array}$ & \multicolumn{2}{|c|}{ Durbin Watson statistic } \\
\hline & 0.408 & 0.166 & 0.092 & & 1.88703 & 2.126 & \\
\hline \multicolumn{2}{|l|}{ Model } & \multicolumn{2}{|c|}{ Regression coefficient $\mathbf{B}^{\mathbf{a}}$} & T-value & Significance & $\begin{array}{l}\text { Collinearity statistic } \\
\text { tolerance }\end{array}$ & $\begin{array}{l}\text { Variance } \\
\text { inflation factor }\end{array}$ \\
\hline \multicolumn{2}{|c|}{ Constant } & 8.165 & & 2.706 & 0.009 & & \\
\hline \multicolumn{2}{|c|}{ Physician-patient relationship } & -0.55 & & -0.792 & 0.432 & 0.844 & I. 185 \\
\hline \multicolumn{2}{|c|}{ KSK } & -0.05 & & -2.272 & 0.027 & 0.850 & 1.176 \\
\hline \multicolumn{2}{|l|}{ PSK } & -0.03 & & -1.359 & 0.180 & 0.479 & 2.086 \\
\hline \multicolumn{2}{|l|}{ Anxiety } & -0.06 & & -0.727 & 0.470 & 0.449 & 2.229 \\
\hline \multicolumn{2}{|c|}{ Family environment } & -0.06 & & -0.231 & 0.818 & 0.884 & 1.131 \\
\hline
\end{tabular}

Note: ${ }^{a} \mathrm{~A}$ high value on the non-adherence scale corresponds to a worse adherence; a higher value of the individual regressor reduces non-adherence, implying an improvement of adherence. 
Our study shows adherence of AYA patients with cancer to be independent of age, gender, religion, and education - a finding consistent with recent studies reported by Kondryn et al and Kennard et al. ${ }^{18,28}$

In addition, our findings on the physician-patient relationship showed no significant correlation to adherence of AYAs with cancer. This differs from the results of Kennard et al who found that physician-patient relationship was an important key for improved adherence. ${ }^{28}$ In our study, AYAs did not feel better informed than older patients, nor did they display a greater need for information. In the case of uncertainty, AYAs were more likely to search the Internet for information. After consultation with a physician, they were more likely to adopt a "wait and see" attitude. This may be indicative of passive and defiant behavior, which in turn might negatively impact adherence and therapy.

AYA cancer patients are more proactive in the case of uncertainty after consultation with a physician; they are more likely to consult their partner, nurses, and other physicians. In comparison with older patients, AYAs with cancer more often believe that physicians ought to improve their communication skills and report to have received therapies that had not been explained to them in detail. Patients from both the groups wished that diagnosis and therapy could be discussed in an open and honest manner. In our study, AYAs were less interested in talking about their most personal problems with their physicians.

In contrast to the studies of Kennard et al and Kyngäs et al, ${ }^{17,28}$ family atmosphere was not correlated to adherence of AYA patients with cancer. A reason for this finding might be that the average age of AYAs was proportionally high at 30.6 years in our study.

Anxiety was not correlated to adherence of AYA patients with cancer. But AYAs with cancer reported a stronger feeling of unwillingness to enter the hospital. AYA patients may feel loss of autonomy, which is in conflict with their need to take part in the decision-making process. Pursuant to current studies, depression, ${ }^{28,44}$ and anxiety ${ }^{45}$ were found to be positively correlated to non-adherence in AYAs.

In our study, perceived mental distress was not related to adherence; this result is consistent with a recent study of Jamison et al. ${ }^{27}$ However, perceived physical illness was significantly related to quality of life. This indicates that a more content patient with physical well-being will be more likely to show therapy adherence and thus show a better outcome. ${ }^{46,47}$

Limitations of our current study need to be considered. The participation rate might have been higher when including only patients of a single hospital, making personal access easier; however, this would not be a population-based study. The different numbers of male and female patients in our study might imply a possible bias. And the relatively small sample size might preclude generalization of our findings. However, our study is unique as it is population-based, unlike all other studies in this field published until now.

\section{Conclusion}

AYAs are a heterogeneous group of cancer patients, who express a stronger need for information and who are more prone to abort therapy as compared to older patients. Psychosocial and communicative skills should be improved. Many other factors, for example, differences in therapy protocols and care, type and place of treatment, may influence adherence, a field that needs further research and clarification in the future. ${ }^{18,43} \mathrm{~A}$ very important issue, requiring future research, is better understanding of media use in AYAs. ${ }^{48}$

\section{Acknowledgments}

Substantial parts of this work were based on collaborative work within the research group AYAROSA in Rostock, including the investigators Inken Hilgendorf, now Klinik für Innere Medizin II, Abteilung Hämatologie, und Internistische Onkologie, Universitätsklinikum Jena, Germany; Peter Kropp, Institute of Medical Psychology and Medical Sociology, Rostock, Germany; Thorid Nielsen, Children's Hospital, University Medicine Rostock, Rostock, Germany; Jessica Klasen, Children's Hospital, University Medicine Rostock, Germany; and Heike Zettl, Clinical Cancer Registry, Rostock, Germany. Substantial support was also given by Devan Ahluwalia. Furthermore, we acknowledge the enormous contribution given by the study subjects.

\section{Disclosure}

The authors report no conflicts of interest in this work.

\section{References}

1. Ferrari A, Thomas D, Franklin ARK, Hayes-Lattin BM, et al. Starting an adolescent and young adult program: some success stories and some obstacles to overcome. J Clin Oncol. 2010;28:4850-4857.

2. Krebs in Deutschland 2009/2010. 9. Ausgabe. Robert Koch-Institut (Hrsg) und die Gesellschaft der epidemiologischen Krebsregister in Deutschland e.V. (Hrsg). Berlin. 2013.

3. Treadgold CL, Kuperberg A. Been there, done that, wrote the blog: the choices and challenges of supporting and adolescents and young adults with cancer. J Clin Oncol. 2010;28:4842-4849.

4. Schmidt C. Lack of progress in teen and young adult cancers concerns researchers, prompts study. J Natl Cancer Inst. 2006;98:1760-1761.

5. Burke ME, Albritton K, Marina N. Challenger in the recruitment of adolescents and young adults to cancer clinical trials. Cancer. 2007;110: 2385-2393. 
6. Bleyer A, Choi M, Fuller CD, Thomas CR Jr, Wang SJ. Relative lack of conditional survival improvement in young adults with cancer. Semin Oncol. 2009;36:460-467.

7. Adolescents and Young Adult Oncology Progress Review Group. Closing the gap: research and cancer care imperatives for adolescents and young adults with cancer (NIH Publication No. 06-6067). Bethesda, MD: Department of Health and Human Services, National Institutes of Health, National Cancer Institute, and the LIVESTRONG Young Adult Alliance; August 2006. Available from: https:/www.cancer.gov/types/ aya/research/ayao-august-2006.pdf. Accessed March 26, 2018.

8. Hayes-Lattin B, Mathews-Bradshaw B, Siegel S. Adolescents and young adults. adolescent and young adult oncology training for health professionals: a position statement. J Clin Oncol. 2010;28: 4858-4861.

9. Morgan S, Davies S, Palmer S, Plaster M. Sex, drugs and rock'n roll: caring for adolescents and young adults with cancer. J Clin Oncol. 2010;28:4825-4830.

10. Stern M, Krivoy E, Foster RH, Bitsko M, Toren A, Ben-Arush M. Psychosocial functioning and career decision-making in Israeli adolescent and young adult cancer survivors. Pediatr Blood Cancer. 2010;55:708-713.

11. Merckaert I, Libert S, Messin S, Millani M, Slachmuyider JL, Razavi D. Cancer patients' desire for psychological support: prevalence and implications for screening patients' psychological needs. Psychooncology. 2010;19:141-149.

12. Kazak AE, Derosa BW, Schwartz LA, et al. Psychological outcomes and health beliefs in adolescent and young adult survivors of childhood cancer and controls. J Clin Oncol. 2010;28:2002-2007.

13. Bleyer A, Barr R, Hayes-Lattin B, et al. The distinctive biology of cancer in adolescents and young adults. Nat Rev Cancer. 2008;8:288-298.

14. Zebrack B, Chesler M, Orbuch T, Parry C. Mothers of survivors of childhood cancer: their worries and concerns. J Psychosoc Oncol. 2002;20:1-26.

15. Hobbie WL, Stuber M, Meeske K, et al. Symptoms of posttraumatic stress in young adult survivors of childhood cancer. J Clin Oncol. 2000;18:4060-4066.

16. Glover DA, Byrne J, Mills JL, et al. Impact of CNS treatment on mood in adult survivors of childhood leukemia: a report from the Children's Cancer Group. J Clin Oncol. 2003;21:4395-4401.

17. Kyngäs H, Mikkonen R, Nousiainen EM, et al. Coping with the onset of cancer: coping strategies and resources of young people with cancer. Eur J Cancer Care (Engl). 2000;10:6-11.

18. Kondryn HJ, Edmondson CL, Hill J, Eden TOB. Treatment non-adherence in teenage and young adult patients with cancer. Lancet Oncol. 2011;12:100-108

19. The World Health Organization. Adherence to long-term therapies evidence for action. Available from: http://www.who.int/chp/knowledge/ publications/adherence_full_report.pdf. Accessed Jan 31, 2018.

20. Hawwa AF, Millership JS, Collier PS, et al. The development of an objective methodology to measure medication adherence to oral thiopurines in paediatric patients with acute lymphoblastic leukaemia - an exploratory study. Eur J Clin Pharmacol. 2009;65:1105-1112.

21. Kyngäs H. Compliance of adolescents with chronic disease. J Clin Nurs. 2000;9:549-556.

22. Thomas DM, Albritton KH, Ferrari A. Adolescent and young adult oncology: an emerging field. J Clin Oncol. 2010;28:4781-4782.

23. Rudd P. In search of the gold standard for compliance measurement. Arch Intern Med. 1979;139:627-628.

24. Ruddy K, Mayer E, Partridge A. Patient adherence and persistence with oral anticancer treatment. CA Cancer J Clin. 2009;59:56-66.

25. Chatterjee JS. From compliance to concordance in diabetes. J Med Ethics. 2006;32:507-510.

26. Waterhouse DM, Calzone KA, Mele C, Brenner DE. Adherence to oral tamoxifen: a comparison of patient self-report, pill counts, and microelectronic monitoring. J Clin Oncol. 1993;11:1189-1197.

27. Jamison RN, Lewis S, Burish TG. Cooperation with treatment in adolescent cancer patients. J Adolesc Health Care. 1986;7:162-167.
28. Kennard BD, Stewart SM, Olvera R, et al. Nonadherence in adolescent oncology patients: preliminary data on psychological risk factors and relationships to outcome. J Clin Psychol Med Settings. 2004;11:31-39.

29. Tebbi CK, Richards ME, Cummings KM, Zevon MA, Mallon JC. The role of parent-adolescent concordance in compliance with cancer chemotherapy. Adolescence. 1988;23:599-611.

30. Vermeire E, Hearnshaw H, Van Royen P, Denekens J. Patient adherence to treatment: three decades of research. A comprehensive review. J Clin Pharm Ther. 2001;26:331-342.

31. McTiernan A. Issues surrounding the participation of adolescents with cancer in clinical trials in the UK. Eur J Cancer Care. 2003;12:233-239.

32. DiMatteo MR, Giordani PJ, Lepper HS, Croghan TW. Patient adherence and medical treatment outcomes: a meta-analysis. Med Care. 2002;40:794-811.

33. Avorn J, Monette J, Lacour A, et al. Persistence of use of lipid-lowering medications: a cross-national study. JAMA. 1998;279:1458-1462.

34. Urquhart J. Compliance and clinical trials. Lancet. 1991;337:1224-1225.

35. Haynes RB, Sackett DL, Taylor DW, Roberts RS, Johnson AL. Manipulation of the therapeutic regimen to improve compliance: conceptions and misconceptions. Clin Pharmacol Ther. 1977;22:125-130.

36. Vermeire E, Hearnshaw H, Van Royen P, Denekens J. Patient adherence to treatment: three decades of research. A comprehensive review. J Clin Pharm Ther. 2001;26:331-342.

37. Hilgendorf I, Freund M, Kropp P, et al. Onkologische Erkrankungen bei Jugendlichen und jungen Erwachsenen - Zahlen aus dem Klinischen Krebsregister Rostock als Arbeitsgrundlage für eine interdisziplinäre Herausforderung [Oncological diseases in adolescents and young adults numbers from the clinical cancer registry rostock as working basis for an interdisciplanry challenge]. Tumor Diagn Ther. 2011;32:85-92. German.

38. Kondryn HJ, Edmondson CL, Hill JW, Eden TOB. Treatment nonadherence in teenage and young adult cancer patients: a preliminary study of patient perceptions. Psychooncology. 2009;18:1327-1332.

39. Petermann F. Testbesprechung Hospital Anxiety and Depression Scale, Deutsche Version (HADS-D). Z Psychiatr Psychol Psychother. 2011;59(3):251-253.

40. Bullinger M. German translation and psychometric testing of the SF-36 Health Survey: preliminary results from the IQOLA Project. Soc Sci Med. 1995;41:1359-1366.

41. Bullinger M, Kirchberger I, Ware J. Der deutsche SF-36 Health Survey. Übersetzung und psychometrische Testung eines krankheitsübergreifenden Instruments zur Erfassung der gesundheitsbezogenen Lebensqualität [The German SF-36 Health Survey. Translation and psychometric testing of a disease-independent instrument for the assessment of health-related quality of life]. Z Gesundh Wiss. 1995;3:21-36. German.

42. Bullinger M, Kirchberger I. SF-36. Fragebogen zum Gesundheitszustand. Handanweisung. Göttingen: Hogrefe Verlag; 1998.

43. Bullinger M. Erfassung der gesundheitsbezogenen Lebensqualität mit dem SF-36-Health Survey. Leitthema: Gesundheitsbezogene Lebensqualität. Bundesgesundheitsblatt Gesundheitsforschung Gesundheitsschutz. 2000;43:190-197.

44. Stewart SM, Lee PW, Waller D, et al. A follow-up study of adherence and glycemic control among Hong Kong youths with diabetes. J Pediatr Psychol. 2003;28:67-79.

45. Blotcky AD, Cohen DG, Conatser C, Klopovich P. Psychosocial characteristics of adolescents who refuse cancer treatment. J Consult Clin Psychol. 1985;53:729-731.

46. Korsch BM, Gozzi EK, Francis V. Gaps in doctor-patient communication: doctor-patient interaction and patient satisfaction. Pediatrics. 1986;42:855-871.

47. Lehmann F, Fontaine D, Bourque A, Côté L. Measurement of patient satisfaction: the Smith-Falvo Patient-Doctor Interaction Scale. Can Fam Physician. 1988;34:2641-2645.

48. European Commission, Directorate-General Health and Consumers and co-ordinated by Directorate-General for Communication: Special Eurobarometer 411: patient safety and quality of care report; June 2014. Available from: http://ec.europa.eu/public_opinion/index_en.htm. Accessed Jan 31, 2018. 


\section{Supplementary material}

\section{AYAROSA questionnaire (English translation)}

\section{A) Personal data}

Gender: $\square$ female $\square$ male Age:_years

B) Education (multi-referencing possible)

$\square$ No school degree $\quad \square$ Special school

$\square$ Lower secondary school $\square$ Secondary school

$\square$ High school qualification $\square$ Higher education degree

\section{C) Family status}

$\square$ Single

$\square$ Partnership, living separately

$\square$ Partnership, living together

$\square$ Married, living separately

$\square$ Married, living together

$\square$ Divorced

$\square$ Widowed

\section{D) Kids/stepchildren}

$\square$ I have no children/stepchildren

$\square$ I have children/stepchildren, (number) aged

\section{E) Residence}

$\square$ I live with my mother and/or my father

$\square$ I live in my own flat

$\square$ I previously lived on my own, but moved back in with my parents

$\square$ I reside with both my parents and at my place of schooling

If yes: $\square$ My therapy is done at the place of education.

$\square$ My therapy is at the place of my parents.

$\square$ Both places are located close to the place of therapy.

F) Education at the time of diagnosis

$\begin{array}{lll}\square \text { Pupil } & \square \text { Trainee } & \square \text { Student } \\ \square \text { Employee } & \square \text { Unemployed } & \square \text { Other: }\end{array}$

G) How much time has passed since the date of diagnosis?
$\square$ Less than 2 weeks
$\square$ 2-4 weeks
$\square 4$ weeks to 2 months
$\square$ More than 2 months

$\square$ Other:

\section{H) My religion}

$\begin{array}{lll}\square \text { No religion } & \square \text { Protestant } & \square \text { Catholic } \\ \square \text { Buddhist } & \square \text { Muslim } & \square \text { Other: } \\ \end{array}$

I) Personal questions concerning coping with the diagnosis

\begin{tabular}{llll}
\hline 1 & 2 & 3 & 4 \\
unconditionally true & mainly true & rarely true & false
\end{tabular}

(answer possibilities valid for questions 1-32, 35-41)

1) Since the diagnosis I am on unsure footing.
2) I regard the therapy as a challenge I have accepted for myself.

3) All of a sudden, I feel like, like a defenceless child.

4) I feel well informed.

5) I decide about my own therapy; the doctors act only as my consultants.

6) The doctors keep me informed about what is happening to me.

7) Since the time of diagnosis I have regained control over my life.

8) I have to prepare myself for new horrors every day.

9) During the medical rounds there are so many people present that one cannot talk about the real issues.

10) During ward rounds I would like to ask the doctors more questions but do not dare.

11) When entering the hospital I feel reluctant.

12) The doctors do not listen to me.

13) I have so many doctors that I do not know who is responsible for me.

14) I also receive information from external specialists.

15) I would share my most personal problems with my doctor.

16) I think doctors would do well to improve their communication skills.

17) Sometimes, although the doctor talks a lot I do not understand a thing.

18) Most doctors just pretend to know a lot of things.

19) I have already been dishonest with my doctor.

20) My doctors have already been dishonest with me.

21) I wish my doctors would act more like a mother/a father toward me.

22) Often I feel like a cog in a gigantic medical machine.

23) Before signing a declaration of consent I always study it first in its entirety.

24) It annoys me when doctors talk about psychological stuff.

25) I am happy to receive all information in an objective, non-emotional manner; I can cry when I am alone.

26) I have the feeling that my doctors are indifferent toward my worries.

27) It is important to me that my hospital room is cozy.

28) I have already had examinations without anyone explaining them to me beforehand.

29) I have already had examinations I was opposed to receiving.

30) Sometimes the doctors share information with my mom and/or dad while keeping me in the dark. 
31) Sometimes the doctors share information with my relatives while keeping me in the dark.

32) The doctors list facts regardless of whether or not I can cope with them.

33) If there are open questions after a talk with the doctor, then I will...

$\square$ search the Internet

$\square$ consult another doctor

$\square$ ask my partner or my friends

$\square$ ask the same doctor again

$\square$ ask a nurse $\quad \square$ just wait and see $\square$ Other:

34) If I am not convinced of a therapy the doctors have decided upon, then...

$\square$ I will insist that another approach be found.

$\square$ I will ask for a talk to the physician until I am convinced.

$\square$ I will give in so that the doctors do not give up on me.

$\square$ I will wait and see.

$\square$ I will secretly change my medication.

$\square$ This situation has not come up as of yet.

35) As a child I always had the feeling that I could talk about everything with my mother and/or father.
36) I have thought about pursuing alternative medical approaches.

37) I have already thought about changing my doctor.

38) I have considered breaking off therapy completely.

39) I can talk about all my problems with my mother and/ or my father.

40) Since the diagnosis I often think about the limitations of my own life.

41) Since the diagnosis I am more conscious of life and am happy about things I did not appreciate before.

42) I receive my therapy $\square$ predominantly as an in-patient

$\square$ predominantly as an out-patient

$\square$ both as an in- and as an out-patient

43) In conclusion, I wish to add:
Adolescent Health, Medicine and Therapeutics

\section{Publish your work in this journal}

Adolescent Health, Medicine and Therapeutics is an international, peer-reviewed, open access journal focusing on health, pathology, and treatment issues specific to the adolescent age group. All aspects of health maintenance, preventative measures and disease treatment interventions are addressed within the journal and practitioners from all disciplines are

Submit your manuscript here: http://www.dovepress.com/adolescent-health-medicine-and-therapeutics-journal

\section{Dovepress}

invited to submit their work as well as healthcare researchers and patient support groups. This journal is included in PubMed. The manuscript management system is completely online and includes a very quick and fair peer-review system. Visit http://www.dovepress.com/testimonials. php to read real quotes from published authors. 